\title{
Entrevista a Antoni Muntadas ${ }^{1}$
}

\author{
An interview with Antoni Muntadas
}

\author{
JoRdi MASSÓ-CASTILla \\ Universidad Complutense de Madrid. \\ jsmasso@pdi.ucm.es
}

Recibido: 24 de abril de 2012

Aprobado: 9 de julio de 2012

\begin{abstract}
${ }^{1}$ Antoni Muntadas (Barcelona, 1942) es una referencia en el videoarte internacional gracias a una extensa carrera, iniciada a finales de los años 60 del siglo XX. Pocos artistas como él han meditado acerca de la conexión entre lo sensorial y la tecnología, reflexión acompañada siempre por una acerada crítica de los medios de comunicación. En los trabajos de Muntadas, la agudización de los sentidos se antoja la única herramienta del receptor frente a los mecanismos de poder y a sus mensajes. Pero este Premio Nacional de Artes Plásticas en 2005 también ha considerado parte fundamental de su trabajo la docencia, impartida en instituciones como el MIT, en la que comparte con sus estudiantes lo que él denomina la "metodología del proyecto". En esta entrevista, que coincidió con la amplia retrospectiva que el Museo Reina Sofía le dedicó en 2012, Muntadas repasa su trayectoria y explica la función que, según él, debe tener el artista como docente.
\end{abstract}

\section{El "entre"}

J.> Tu última exposición en Madrid, Between [octubre 2011 - febrero 2012], aludía en su título a un "entre" que sugiere un espacio equidistante que deshace toda disyuntiva impuesta desde el exterior. ¿Cómo concibes este ámbito intermedio en el caso del arte? ¿Respondería a una posición política?

A.M.> La palabra "entre" la he usado en obras como Between the Lines [1979] o Between the Frames: the Forum [1983-1991]. Ha sido, pues, bastante recurrente en mi trabajo, si bien creo que detrás de su uso no hay una idea de evolución y de insistencia; simplemente es un concepto que circula. Mi forma de trabajar se basa en estructuras de trabajo y, a veces, en dicotomías como "subjetividad/objetividad", "personal/público"... Estas estructuras dicotómicas me permiten organizar los trabajos, que se sitúan normalmente en los "entre" de esos pares de términos, aunque pueden emplazarse más cerca de uno que del otro. Esta situación puede, además, cambiar, pues siempre existen matices, sobre todo si hablamos de conceptos. En el caso de las ideas de objetividad y de subjetividad, he hablado de una "subjetividad 
crítica" como búsqueda de objetividad. Está próxima a ella, pero no llega a producirse una identificación pues no es posible alcanzar tal objetividad. El arte es percepción, percepción sensorial, e información, y eso es variable. Todos estos elementos son difusos y de ahí que esas dicotomías sean fluidas, casi gaseosas, como diría Zygmut Bauman.

En definitiva, el "entre" se sitúa en estas dicotomías y se refiere a las posiciones que se ocupan ante ellas, siempre variables. Por ejemplo, Emisión / Recepción [1974] permite ver que esos flujos cambian. La emisión cambia según el espacio, la posición, el ambiente, la luz... Y con la recepción sucede lo mismo. Aun así, en Emisión/ recepción hay una emisión que es direccional y una recepción más o menos pasiva, pero cambiante. Por eso, mis planteamientos invitan a pensar. Son dispositivos y estructuras reflexivas que me sirven a mí, si bien están hechos para ser visto, se extienden a la audiencia. Cada uno tiene su narrativa y sus estructuras.

J.> A lo que invitas a los espectadores entonces es a descubrir y morar ese espacio del "entre"...

A.M.>Sí, y a que se sitúen. Es la audiencia la que, al situarse en ese "entre", lo cambia, lo desplaza. Al percibirlo, puede entenderlo críticamente o puede compartir mi posición, pero en cualquier caso esas estructuras de interpretación son cambiables. No quiero entrar en la idea de la "obra abierta", pero es cierto que la interpretación implica unos grados de percepción y de información. Los receptores detectan cosas. Unas les interesan más que otras, según puedan asociarlas (por los grados de información de que dispongan) a algo que habían pensado antes. O bien les hacen pensar algo nuevo. La activación es, para mí, fundamental, y de ahí que acuñara la frase Warning: perception requires involment [Atención: la percepción requiere compromiso]. Entrar en una obra es un trabajo que pide involucración. Las estructuras políticas, económicas, sociales... hacen que desarrollemos cierta capacidad de percepción de cosas que no están ni catalogadas ni definidas según los términos estéticos existentes -"belleza", "arte"...-, pero que son evidentes.

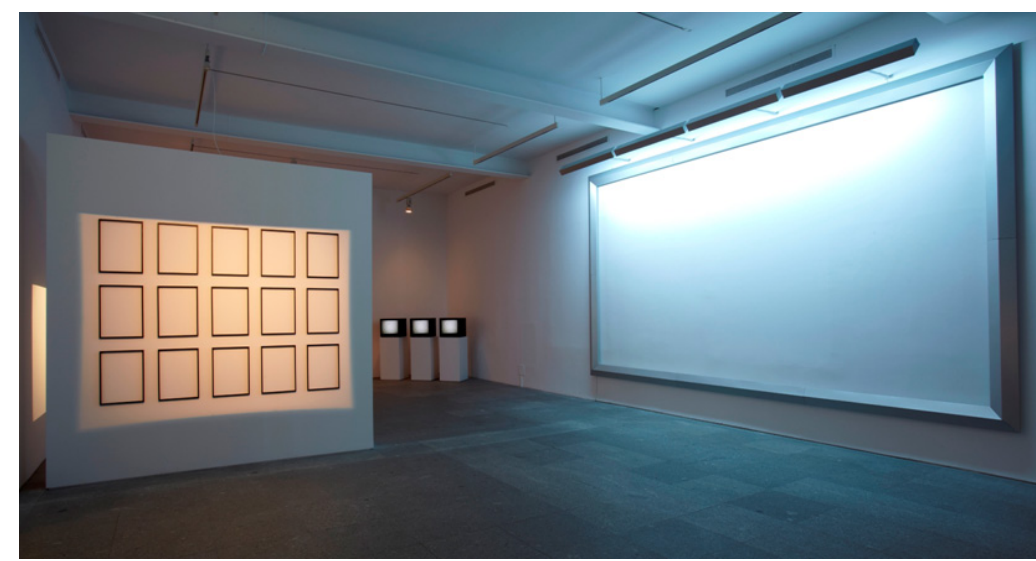

Figura 1. Exposición 2011. (Archivo personal del artista. Joaquín Cortés, 2011). 
J.> Exposición [fig. 1] es una obra emblemática en tu trayectoria. De hecho, ocupó un lugar privilegiado en tu última exposición en el Museo Reina Sofía. La sala, llena de dispositivos en blanco, sin imágenes, invita a preguntarse qué contiene esta instalación porque no es exactamente la nada, sino un vacío inquietante...

A.M.>Este trabajo se hizo en Madrid en 1985 en un antiguo parking, el de la galería Fernando Vijande, un espacio enorme. En aquel momento estábamos en plena movida madrileña, con toda aquella explosión de color, música, barroquismo... En ese contexto, se recibió con frialdad. No hubo casi respuesta, salvo, que recuerde, un escrito de Manuel Antolín Rato en Cuadernos del norte, un artículo en Avui y un cassette de audio que me hizo llegar Alberto Iglesias con una interpretación musical de la instalación. Esto es lo que recuerdo de una exposición que duró casi tres meses, el único feedback.

Esta obra habla de lo que representa una exposición. Si hay un trabajo que, en cierta forma y en cierta clave irónica, pueda considerarse por sí solo una retrospectiva de mi obra, es éste. Incluye todos los medios que he ido utilizando, pero en un "grado cero", pensando en el espacio físico, en cómo se presenta, en las paredes de las galerías, en lo que supone una exposición, en los límites del cuadro, en todos los dispositivos representativos... La obra se ocupa de la representación en un sentido muy amplio. No de la representación de la imagen, sino de cómo se pueden transmitir ciertas cosas con los dispositivos definidos por la historia del arte. Y hay, además, un elemento que puede pasar desapercibido para el público, como es la luz. La selección de la luz es para mí muy importante, pues cada uno de esos dispositivos tiene una iluminación totalmente diferente y un distinto grado de calor, de frío, de intensidad de recorte.

J.> Había pensado que podría ser un espacio del "entre" y una forma de hacer visible lo invisible, que lo que hay detrás de la imagen es esto: la nieve de la pantalla.

A.M.> A eso me refería con lo del "grado cero de información", ese punto en que la imagen está latente pero la estás componiendo, te estás proyectando en ella. Es como una acumulación de cosas que has visto: el cuadro, las fotografías, la valla publicitaria, una serie de dibujos, de vídeos... De alguna manera hay una narrativa, aunque bastante abierta. Es cierto que es uno de los trabajos que siempre ha costado más catalogar, incluir en una tendencia. A mí, al igual que sucede con el "estilo", la catalogación del trabajo no me importa. Cada proyecto genera su propia energía, necesita su propia dinámica y se visualiza y representa de su propia manera. Por eso me interesa la manera en que el receptor lo ve. 


\section{El público}

J.> La forma en que te diriges en tus proyectos al público sugiere que consideras que tu función social en tanto que artista es la de educar al público, hacerle ver los engranajes que permanecen ocultos, situarle en el "entre".

A.M.> La palabra "educar" me parece dura. Bien es cierto que desarrollo una práctica docente, pero ese término resulta duro. Es necesario introducir una cierta distancia, y por eso prefiero otros términos, "pedagogía", quizás, que tamizan la idea de "educación" que, aunque de connotaciones muy amplias, contiene algo que implica una responsabilidad que no quiero asumir porque es casi autoritaria. Las experiencias que he vivido en las clases me han permitido ser consciente de lo que significa educar y de la autoridad que confiere. He realizado un trabajo, About Academia [2009-2011] [fig. 4], en el que trato esta cuestión. Harvard me propuso desarrollar un proyecto y decidí hablar de la academia en el contexto de Cambridge, MIT [Instituto de Tecnología de Massachusetts] y Harvard: la academia no como transmisora de conocimientos, sino como una autoridad que administra poder en un sentido foucaultiano. En definitiva, mi trabajo es un compartir unos procesos de conocimiento, como un taller. Esto tiene una parte pedagógica, si se quiere, pero con matices: no rehúyo la idea de "educación", pero concibo mis obras como situaciones que invitan a reflexionar.

J.> Pero al mismo tiempo, aun entendiendo esos recelos, constantemente enfatizas en tus textos la necesidad de que el público no sea un consumidor pasivo. De hecho, tus mensajes hacia él, como el que has mencionado antes, "Atención, la percepción requiere compromiso" [fig. 3], son muy claros al respecto.

A.M.> Yo trasmito una reflexión, la comparto, pero de ninguna manera querría que se entendiese que le digo al público: "esto es lo que hay que hacer". Me opongo totalmente a eso. Más bien lo que lanzo es un: "atención", para descubrir un territorio que hay que mirar y desengranar. Pongo un punto de atención sobre cosas que me interesan y que creo que podrían interesar a otras personas, pues están dentro de los engranajes socio-humanistas o político-económicos en que nos movemos. Es, pues, una intervención subjetiva y personal; intento aleccionar para mirar, sin caer en situaciones dogmáticas. Es una posición más próxima a que cada uno se cree su manera de pensar las cosas. Por eso mis clases no pretenden ser otra cosa que una invitación a crear una metodología de proyecto, siendo consciente de cada fase o decisión. 


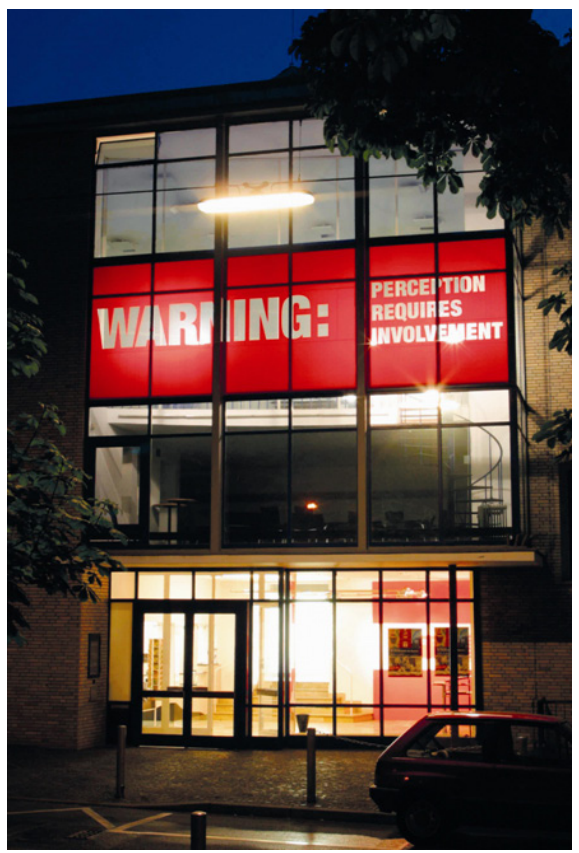

Figura 2. On Translation: Warning... 1999- (Archivo personal del artista. Sascha Dressler, 2003).

J.> En los últimos años se ha establecido una contraposición entre un arte que, según Jacques Rancière, busca generar comunidades disensuales opuestas al orden establecido, y ese otro "arte relacional" del que habla Nicolas Bourriaud, que fomenta nuevos vínculos entre los receptores. Es curioso comprobar cómo en los años 70, en trabajos como Cadaqués - Canal Local [1974] o Barcelona Distrito Uno [1976], anticipaste algunos aspectos que veinte años más tarde reaparecerán en el contexto de esta polémica. ¿Detrás de la idea de trabajar con los receptores en grupo había una voluntad de crear comunidades o fomentar relaciones?

A.M.> En primer lugar, debo reconocer que me siento próximo a la idea de comunidad de Maurice Blanchot, o a la del proyecto de Valentín Roma [historiador y profesor, fue el comisario de la exposición La comunidad inconfesable que se presentó en e la $53^{\text {a }}$ Bienal de Venecia] que no sólo tienen que ver con el arte, sino con ámbitos mucho más amplios: la sociedad, la política, el individuo. En mi caso, habría que decir que el trabajo en equipo ha sido muy importante, pues muchos de esos proyectos no habrían salido adelante si no hubiese colaborado con otras personas. Hoy en día hay que desmitificar la idea del artista que crea en la soledad de su estudio. Las cosas han cambiado y se trabaja con más gente, en diálogo e ideando proyectos. Por un lado hay entonces un trabajo colaborativo en equipo. Pero por otro, es evidente que hay "comunidad" no sólo en el caso de la producción, sino también en el de la recepción. En ésta no se crea una comunidad tan definida como, por ejemplo, la del público 
que asiste a una conferencia o que en un auditorio escucha un concierto. No soy consciente del público que van a tener mis trabajos, pero sí sabes que alguien los va a recibir, y eso es importante, pues creamos para otras personas. Ahora bien, la manera en que esta comunidad se constituye no es mecánica, ya que en ese caso estaríamos hablando de publicidad y de de política, de cuáles son los índices definidos por una audiencia televisiva, por una campaña política. El artista es menos consciente de las comunidades que se crean, pero en todo caso hay una voluntad de que existan.

J.> Abundando en lo anterior, no sé si concibes a ese público al que pretendes llegar como un espectador solitario, que contempla tu obra en la sala de un museo, o si por el contrario buscas que la recepción no sea únicamente individual y solitaria, sino en grupo, $\mathrm{y}$ hasta fuera del espacio expositivo.

A.M.> Sí, también busco esto último, pero es imposible conocer cuál es el resultado que se consigue. Es muy difícil conocer, por ejemplo, quién usa The File Room, o saber qué resultados obtuvo Cadaqués - Canal Local o de Barcelona Distrito Uno. En el caso de Cadaqués, una población con 3.000 habitantes que en aquella época [1974] aumentaba hasta los 60.000-80.000 en verano, mi intención era trasladar programas televisivos emitidos en inverno a la realidad estival, turística. En cierta forma, aunque esos programas estaban dirigidos a los habitantes habituales, indirectamente su destinataria era la población flotante que no conoce cuál es la realidad del invierno, diferente a la de los meses de julio y agosto, de turismo y consumo.

Barcelona Distrito Uno tenía unas connotaciones directamente políticas, pues era justo el momento [1976] posterior a la muerte de Franco. La transición comenzaba, la gente se organizaba en grupos vecinales... En esa obra trabajé con grupos de comunidades de vecinos del barrio creando otro tipo de información distinta a la dominante, la que difundía Televisión Española. Al cambiar una televisión única por una televisión local en otro idioma y más próxima, es evidente que se crea otra comunidad.

\section{La obra de arte como discurso y archivo}

J.> A la hora de describir tu propio trabajo, sueles recurrir al término "discurso". Lo que haces es, según tus propias palabras, "sostener un discurso". Ya que antes has mencionado a Foucault, que analiza los discursos y los mecanismos para controlarlos, ¿habría algún paralelismo entre su concepción del discurso y la tuya?

A.M.> Quisiera matizar algo. Lo primero que hago cuando doy una clase es escribir 40-50 palabras para "traficar" con ellas a partir de su etimología, para unificar así el vocabulario. Es evidente que "discurso" remite popularmente al discurso político, a una perorata. Pero cuando empleo el término "discurso", lo hago para rehuir la idea formalista del "estilo", como cuño que permite decir: "esto está creado por mí". Pretendo crear un discurso a través de obras con un estilo muy diferente. No creo que en mi trabajo pueda reconocerse la autoría a partir de un estilo. Habría que conocerlo muy bien para asociar una obra conmigo. El estilo es, en definitiva, algo fácilmente reconocible y buscado por el artista, que da así valor a su trabajo. Entiendo 
que hay una ruptura con esta idea, no de una manera drástica, pues tengo obras que permiten señalar un parecido formal o determinadas asociaciones, pero en general sí que prefiero que se asocien con el discurso más que con el estilo. El discurso es una relación entre los trabajos que conforman un todo. Así que cuando hablo de "discurso" es para distanciarme de la idea de "estilo" que, insisto, tiene que ver con problemas formales. Pero históricamente en el arte llega un momento en que es difícil señalar parecidos en las obras. ¿Podrías definir el estilo de trabajos que tienen que ver no sólo con imágenes, sino que son sistemas, o instalaciones, o collages? No lo sé. Pero volviendo a Foucault, estoy de acuerdo con que un discurso puede ser una suma de discursos.

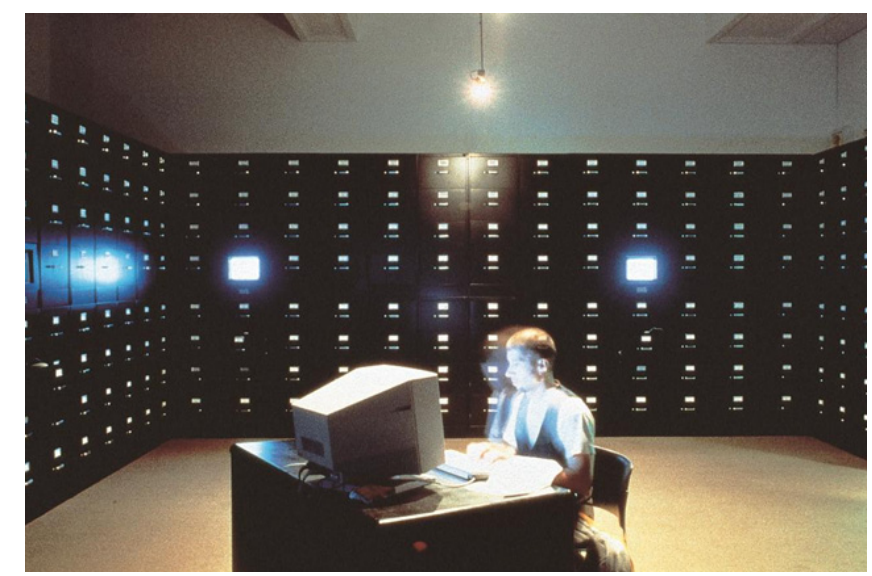

Figura 3. The File Room. (Archivo personal del artista. Román Lores Riesgo, 1994).

J.> En The File Room [1994] [fig.3], otra de tus obras más conocidas, se hace evidente, quizás como en ninguna otra, tu preocupación por la memoria a través de la presentación de un gran archivo de la censura. En otros trabajos, como Media sites / Media Monuments: Washington [1981] o Buenos Aires [2007], te acercas a la idea del "monumento" como lo que permite el recuerdo pero que a la vez puede llegar a ocultar sucesos asociados al evento conmemorado. ¿Cómo describirías el tratamiento que haces de la memoria y del archivo?

A.M.> El archivo es, para mí, un dispositivo de trabajo. A veces lo creo yo y otras simplemente accedo a él. Para cada proyecto, en especial cuando llevan un tiempo, elaboro una especie de documentación, de proceso de recolección, que es lo que considero como mi propio archivo. En mi caso, el archivo personal y la investigación se confunden. Lo que el archivo genera son las fuentes para después crear un trabajo. Por eso no concibo el archivo si no está activado. Between the Frames: the Forum, una obra sobre el sistema del arte que duró diez años, está ahora [enero 2012] en el MACBA. El resultado final se halla en el museo, pero el archivo, en el centro de documentación. Si uno es la obra, el otro es la investigación, una fuente a disposición 
de especialistas que deseen consultar esas 150 entrevistas para saber lo que dicen personas como Lucy Lippard, Pierre Restany o Benjamin Buchloch, sobre el mundo del arte. Por tanto, creo que el archivo es una acumulación inerte de material organizado de diferentes maneras, que para adquirir un sentido necesita ser activado para algo específico. En una obra como The File Room, el archivo se genera partiendo de un foco, el de la "censura cultural", que se pedía al público que activase.

J.> En esas obras parece que prácticamente te conviertes en un centro de documentación. ¿Cuál sería el vínculo con esos otros trabajos en los que no proporcionas el archivo sino la memoria, la memoria de cosas que quedan ocultas? ¿Existe una relación entre el archivo y la recuperación del pasado por medio de la búsqueda de lo que está debajo de los monumentos, de los espacios públicos?

A.M.> Déjame poner el ejemplo del proyecto de Bremen, On Translation: Erinnerungsräume [espacios de memoria] [2004], que presenta situaciones y ruinas arquitectónicas características de ciudades alemanas de posguerra. Lo que me interesaba era buscar y explorar espacios que habían tenido unas connotaciones políticas y que luego se habían transformado. ¿Qué sucede con esos lugares? En este trabajo la idea de memoria y monumento se entremezclan. Personalmente no estoy en contra de los monumentos, pues tienen su importancia en las ciudades como memoria histórica, pero ha habido un exceso y una acumulación que han desvirtuado lo que podrían tener de similar interés o genuino. En Espacios de memoria desaparece uno, el obelisco, pero lo que surge en forma de publicación es otro monumento, más horizontal y más narrativo. En ese sentido sí que me interesa la idea de monumento, ya que es una forma de recordar, pero de recordar desde lo presente. Pero, claro está, son trabajos muy específicos para una ciudad, un lugar y una audiencia. Creo que en ciertos momentos es mejor hablar de lo local que de lo global. Si lo local funciona puede alcanzar lo global.

\section{El contexto}

J.> En el caso del proyecto de Bremen, has subrayado la importancia de que tuviera lugar en un contexto determinado, ante una audiencia concreta. Eso me lleva a preguntarte por la importancia que la noción de "contexto" tiene en tu trabajo. Fuera de él, ¿tus obras cambian? En caso afirmativo, ¿sería un efecto buscado?

A.M.> En cada trabajo tengo en cuenta el contexto. Si acometo un proyecto en Puerto Rico, como On Translation: el tren urbano [2005], soy muy consciente de dónde estoy y, por decirlo así, la experiencia me enriquece con lo que allí ha pasado, con el background del lugar. Otro ejemplo: Stadium, una instalación de 1989 que a día de hoy tiene más de 15 versiones, fue recontextualizada para la exposición de Madrid de 2011 para ofrecer unas claves al público que le pueden resultar próximas. En cada montaje se mantiene un $60 \%$ de material original y el $40 \%$ restante es nuevo. Siempre se dan situaciones que el público puede sentir como más cercanas para crear así ciertas complicidades que considero son importantes. Los trabajos no son una imagen única, sino unos sistemas de trabajo en los que la obra, el archivo y la memoria 
confluyen. En el caso de Stadium, desde el punto de vista físico de la construcción, lo que se mantiene es la idea de las columnas, de los elementos simbólicos... En resumen, diría que mi trabajo es sobre el contexto y para el contexto. En las obras para espacios públicos es importante trabajar, no para el lugar, sino también con el lugar. El espacio público no es el espacio protegido de galerías y museos, cuyo público acude expresamente a él, sino que lo encuentras inesperadamente. Estas intervenciones públicas, sobre todo si están ligadas a una comunidad, propician el cambio de trabajar para a trabajar con, lo que plantea una dimensión de tiempo muy importante.

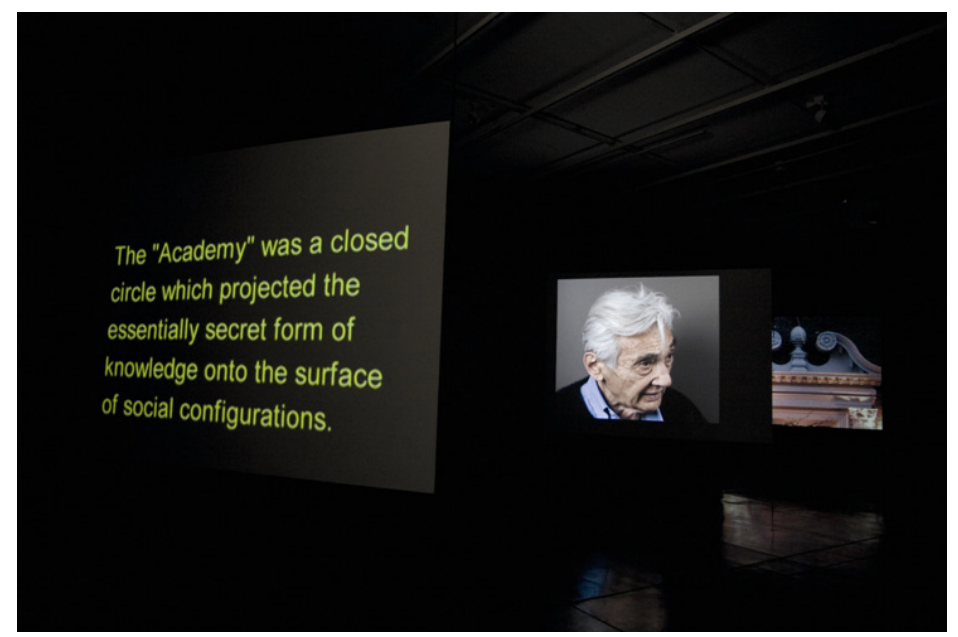

Figura 4. About Academia. (Archivo del artista, 2011).

$\mathrm{J} .>$ Has indagado en tu propio contexto como artista y profesor en trabajos como About academia [fig. 4] o Between the frames, en los que te conviertes en un investigador que se sumerge en esos ámbitos -el del arte como institución y el de la docencia- por medio de preguntas a quienes ocupan una posición idéntica a la tuya, bien como artistas, bien como profesores, y sin embargo adoptas un distanciamiento para interrogarlos...

A.M.> Son dos contextos, el del mundo del arte, y el de la academia, en los que, como has visto muy bien, participo y que deseo confrontar. Esto último es un aspecto importante. Usar la entrevista como herramienta de trabajo me ha parecido importante, pues a veces perdemos la referencia de lo que significa. La entrevista es un instrumento que, a través de la conversación, intenta suscitar preguntas para tratar de esclarecer o de saber más. Y me parece que es un dispositivo a veces se banaliza por culpa de los medios de comunicación. El sistema de entrevistas de larga duración es interesante por cuanto permite que los roles se interpreten de diferente manera. Los roles, en el caso del mundo del arte; en el de la academia, la manera de interpretar o de traducir unas responsabilidades. 
Entre Between the frames, que se inicia hacia 1982 y llega a 1993, y About Academia, que comienzo entre 2006 ó 2007 y presento en 2011, transcurren quince años. Se trataba de dos contextos que me interesó analizar. En el caso de caso Between the Frames, la iniciativa fue mía, mientras que en About academia recibí una invitación por parte de Harvard para hacer un proyecto. En este último aparecen personas pertenecientes al campo de la lingüística, la geografía o la arquitectura. Trataba de que esta investigación fuese amplia en el sentido de que tomase en cuenta el mundo de la academia desde un punto de vista lato. Además, por el hecho de que fuera una propuesta de Harvard y ya que yo llevaba tiempo en MIT, pensé que era interesante afrontarlo desde el contexto de Cambridge, si bien posteriormente añadí gente externa a la institución, como Carol Becker, Mark Wigley o David Harvey. En cualquier caso, esta obra tiene que ver más con el ejercicio del poder en la academia que con la diseminación de conocimientos.

$\mathrm{J} .>$ Por tu parte, esta labor te exige tomar un distanciamiento, pues aparentemente en las preguntas eres muy aséptico, no te involucras, no hablas de colega a colega, sino más bien como un observador, alguien ajeno que se interesa mostrando una cierta curiosidad...

A.M.> Sí, en Between the Frames, sólo encuentras ese diálogo entre colegas en el epílogo, en el que aparecen algunos creadores que han trabajado la cuestión del "sistema" y a quienes les pregunto no tanto por el rol del artista, sino por el rol de ese mismo sistema.

J.> Antes señalabas que la academia y el mundo del arte son centros de poder...

A.M.> Llevo muchos años en el MIT, largos periodos largos en condición de research fellow, visiting professor o, desde hace unos años, professor of the practice. Siempre he buscado tener una distancia. No estoy haciendo una carrera académica y hay aspectos en que me beneficio de tener mis libertades, pero también mis desventajas, como la falta de seguridad o de una pensión de jubilación, pero he evitado tener que formar parte del corpus de la academia de una manera automática, pues aparte de lo aburrido que puede ser, tiene mucho de mecánico y administrativo. Esta posición me otorga una cierta actitud, que me permite lanzar determinadas preguntas a gente del MIT, de Harvard. No es que no tenga nada que perder, pero es cierto que un profesor asociado no puede hacerlo porque se truncaría su carrera. Así que, en cierta manera, estás dentro pero tomando una cierta distancia. Es una situación de dentro/fuera.

\section{Espacio, tiempo y escritura}

J.> Una constante en tu trayectoria es la reflexión acerca de los espacios y de lo que hay detrás de ellos, oculto. Por contra, el tiempo está igualmente presente, pero su presencia no es tan explícita y obvia como el caso del espacio. ¿Cómo relacionas tu obra con una meditación sobre el espacio y el tiempo? 
A.M.> El inglés dispone de palabras como "space", "place" y "site". El "sitio" entraña unas afinidades de relación y de uso, de especificidad. El "lugar" y el "sitio" están más ligados al contexto, pues así como el "espacio" es abstracto, a la manera de las tres dimensiones, pienso el lugar como situado en un mapa, en una cartografía. El "sitio", a su vez, podría ser más un espacio más "micro" que el lugar, al estar situado en un espacio más interior. Por eso, incluso en lugar de esas diferencias entre "espacio", "lugar" y "sitio", siendo más concreto habría que hablar de "microlugar" o de "macrolugar", de situaciones de territorio... Concibo el territorio más bien en una situación geográfica que tiene que ver con una topografía y una geografía. Territorios que no son urbanos, sino geográficos, paisajes.

En cuanto al tiempo, llevo bastante tiempo usando el concepto de "Time specific". Empecé a emplearlo cuando se hablaba de "site specific", para referirme a trabajos que tienen que ver con la manera como se relacionan con el público. Hay obras que son muy claras al respecto. Una de ellas es On Translation: Die Stadt [1999-2004]. Tenía que ver con el hecho de que las ciudades de Gratz, Lille y Barcelona habían sido elegidas capitales culturales de Europa. Si hubiese presentado el trabajo en el momento en que tenían lugar esas manifestaciones, éste habría sido absorbido por ellas y habría parecido que formaba parte de las celebraciones, cuando lo que quería era adoptar una distancia crítica. Por eso desarrollé el proyecto a toro pasado, cuando los acontecimientos habían acabado, para evitar confusiones. Así, cuando el público ya ha visto lo que estas capitales han podido dar de sí, las cosas positivas o negativas, pueden formarse una opinión a posteriori porque ya están en condiciones de poder evaluar.

J.> Para cerrar esta conversación, quisiera preguntarte por la relación entre escritura e imagen en tu trabajo. ¿Cómo te planteas la relación que puede haber entre ambas?

A.M.> En general, la imagen es para mí más ambigua que las palabras. Estas últimas, tal y como yo las entiendo, tratan de ser una interpretación de mi vocabulario personal. Por otro lado, no soy partidario de crear grandes textos teóricos. Siempre son textos cortos, a modo de notas: mis notas de proyectos son también notas de intenciones. También trabajo con transcripciones de conversaciones y, dentro de las obras, uso textos y de palabras. En este caso, estos términos que aparecen aislados serían palabras clave a modo de una cierta acupuntura sobre una situación o un proyecto. La aparición de las palabras en los vídeos obedece a que es una manera de puntualizar o reforzar la imagen sin caer en el subtítulo. Porque una imagen a veces es mucho más ambigua que la palabra. Al decir ambigüedad lo digo en un sentido positivo. Como una imagen está muy ligada a la historia que tiene detrás (cuándo se ha creado, por quién...), los contextos en los que se hacen los trabajos son importantes. De ahí ese interés en los textos contextuales que ayudan a entender dónde, cuándo y cómo se hicieron los trabajos. No se trata de explicar, sino de dar un mínimo de cosas para explicar un trabajo que está ligado a una situación. 